\title{
STRATEGI BRANDING DESTINASI WISATA PANTAI TANJUNG KELAYANG (OBJEK STUDI: PANTAI TANJUNG KELAYANG, KABUPATEN BELITUNG, PROVINSI KEPULAUAN BANGKA BELITUNG)
}

\author{
Valencia $^{1)}$, Priyendiswara Agustina Bela ${ }^{2)}$, Bambang Deliyanto ${ }^{3)}$ \\ 1)Program Studi S1 PWK, Fakultas Teknik, Universitas Tarumanagara, avlentcia@gmail.com \\ 2)Program Studi S1 PWK, Fakultas Teknik, Universitas Tarumanagara, hedy.agustina@gmail.com \\ 3)Program Studi S1 PWK, Fakultas Teknik, Universitas Tarumanagara, deli.bambang@gmail.com
}

Masuk: 10-08-2020, revisi: 08-09-2020, diterima untuk diterbitkan: 25-09-2020

\begin{abstract}
Abstrak
Pulau Belitung sedang gencar mendorong sektor pariwisata sebagai sektor andalan. Salah satu objek wisata yang mulai banyak dilirik wisatawan di Belitung adalah Pantai Tanjung Kelayang. Pantai ini telah menjadi objek wisata mass tourism yang rutin dikunjungi di Belitung. Pantai Tanjung Kelayang tak hanya dikenal akan pemandangan pantai bersih dan perairan jernihnya saja namun juga sebagai titik start penyeberangan untuk melakukan kegiatan tur pulau. Kini Pantai Tanjung Kelayang harus bersaing dengan destinasi wisata lainnya yang telah memiliki citra yang lebih kuat dan telah dikenal wisatawan sejak lama. Pantai Tanjung Kelayang memiliki potensi yang besar untuk menjadi pantai dengan brand yang lebih dikenal namun masih terdapat keterbatasan aspek penunjang wisata yang masih kurang serta upaya promosi yang belum efektif. Studi ini bertujuan untuk memberikan usulan strategi yang mengacu pada komponen-komponen destination branding untuk memperkuat citra destinasi dan membangun sisi kompetitif destinasi wisata. Studi dilakukan dengan menggunakan pendekatan kualitatif dan kuantitatif dengan metode analisis deskriptif. Hasil studi menghasilkan usulan strategi penguatan branding dari berbagai aspek yaitu lansekap, infrastruktur, stakeholder dan sikap kota seperti penambahan keragaman atraksi wisata baru dan fasilitas wisata, peningkatan peran partisipasi komunitas dan masyarakat dan kualitas pelayanan serta upaya promosi berupa pemilihan media promosi dan jenis produk wisata yang akan dipromosikan.
\end{abstract}

\section{Kata kunci: Branding; Destinasi Wisata; Strategi}

\begin{abstract}
Belitung Island is aggressively pushing the tourism sector as a main sector. One of the attractions that many tourists are starting to see in Belitung is Tanjung Kelayang Beach. This beach has become a mass tourism attraction that is routinely visited in Belitung. Tanjung Kelayang Beach is not only known for its clean coastal scenery and clear waters but also as a starting point for island hopping activities. Now, Tanjung Kelayang Beach has to compete with other tourist destinations that have a stronger image and have been known by tourists for a long time. Tanjung Kelayang Beach has great potential to become a beach with a better known brand but there are still limited aspects of tourism support that is still lacking and promotion efforts that have not been effective. This study aims to provide a proposed strategy that refers to the components of destination branding to strengthen the image of the destination and build the competitive side of the tourist destination. The study was conducted using qualitative and quantitative approaches with descriptive analysis methods. The results of the study produced a proposed strategy to strengthen branding from various aspects, namely landscape, infrastructure, stakeholders and city behaviour such as the addition of diversity of new tourist attractions and tourist facilities, increasing the role of community and community participation and service quality as well as proposing promotional efforts in the form of selecting promotional media and types of tourism products.
\end{abstract}

Keywords: Branding; Strategy; Tourism Destination 


\section{PENDAHULUAN}

\section{Latar Belakang}

Sektor pariwisata merupakan salah satu sektor yang tengah digiatkan oleh pemerintah Indonesia saat ini. Pariwisata diyakini mampu menjadi penyumbang devisa terbesar bagi negara dan daerah. Kabupaten Belitung saat ini juga tengah gencar mendorong sektor pariwisata sebagai sektor andalan.

Belitung selama ini dikenal akan Laskar Pelangi. Namun fenomena film tersebut dapat memudar seiring dengan berjalannya waktu sehingga diperlukan sesuatu yang baru sebagai ikon khas pariwisata Belitung untuk menarik wisatawan. Saat ini, jenis wisata yang mulai dilirik oleh wisatawan di Belitung adalah wisata pantai dan pulau. Hal ini terlihat dari paket wisata yang ditawarkan di Belitung yang selalu memiliki 1 hari untuk paket island hopping.

Pantai Tanjung Kelayang yang terletak di sisi utara pulau Belitung, memiliki potensi yang besar dibandingkan dengan destinasi wisata lainnya yang ada di Belitung. Menurut Dinas Pariwisata Kabupaten Belitung, Pantai Tanjung Kelayang telah menjadi objek wisata mass tourism yang rutin dikunjungi oleh wisatawan dan 99\% wisatawan yang datang berkunjung ke Belitung dipastikan mengunjungi Pantai Tanjung Kelayang dan pulau-pulau di sekitarnya sehingga dapat dikatakan destinasi wisata ini sudah memiliki sedikit exposure dari wisatawan. Pantai Tanjung Kelayang juga sudah termasuk ke dalam KSPN dan destinasi prioritas pariwisata nasional serta didukung percepatan pengembangannya melalui KEK.

Pantai Tanjung Kelayang tak hanya dikenal akan pemandangan pantai bersih dan perairan jernihnya saja namun juga sebagai titik start penyeberangan untuk melakukan island hopping ke Pulau Lengkuas, Pulau Kelayang, dan pulau-pulau sekitar lainnya. Kini, pantai Tanjung Kelayang harus bersaing dengan destinasi wisata lainnya yang telah memiliki citra yang lebih kuat dan telah dikenal oleh wisatawan sejak lama.

\section{Rumusan Permasalahan}

Pantai Tanjung Kelayang memiliki potensi yang besar untuk menjadi pantai dengan brand yang lebih dikenal. Untuk memiliki branding yang kuat diperlukan citra destinasi yang kuat pula. Citra destinasi terbentuk berdasarkan hasil pengalaman dan pengetahuan gambaran yang dimiliki oleh wisatawan namun saat ini citra destinasi wisata masih belum kuat dibandingkan dengan destinasi lainnya akibat keterbatasan aspek penunjang wisata yang masih kurang serta upaya promosi yang belum efektif.

\section{Tujuan}

Tujuan penelitian yaitu untuk memberikan usulan strategi yang mengacu pada komponenkomponen destination branding untuk memperkuat citra destinasi dan membangun sisi kompetitif destinasi wisata serta upaya promosi destinasi yang tepat untuk mempromosikan serta mengkomunikasikan janji dari branding yang akan didapatkan dari kunjungan wisata.

\section{KAJIAN LITERATUR}

Menurut Dickman (1997), komponen pariwisata meliputi atraksi, aksesbilitas, akomodasi, amenitas dan aktivitas. Menurut Aaker (2002), brand adalah sebuah janji seorang penjual/perusahaan untuk konsisten memberikan nilai, manfaat, fitur dan kinerja tertentu bagi pembelinya. Menurut Ritchie (1998), destination branding didefinisikan sebagai sebuah nama, simbol, logo, tanda kata atau grafis lain yang mengidentifikasi dan membedakan destinasi. Selain itu, destination branding menyampaikan janji pengalaman perjalanan yang tak terlupakan yang secara unik terasosiasi dengan destinasi. 
Menurut Kavaratzis (2008), image dapat dikomunikasikan melalui tiga jenis komunikasi yaitu komunikasi primer, sekunder dan tersier. Komunikasi primer meliputi:

- Landscape (urban design, architecture, public space, public art)

- Infrastructure (Aksesbilitas dan fasilitas)

- Organisational and administrative structure (komunitas, partisipasi masyarakat, kerjasama sektor publik dan privat)

- Behaviour (visi, kualitas pelayanan, events, insentif keuangan)

Komunikasi sekunder meliputi iklan, public relations, desain grafis dan penggunaan logo. Komunikasi tersier merujuk pada pemasaran dari mulut ke mulut yang diperkuat oleh media dan komunikasi.

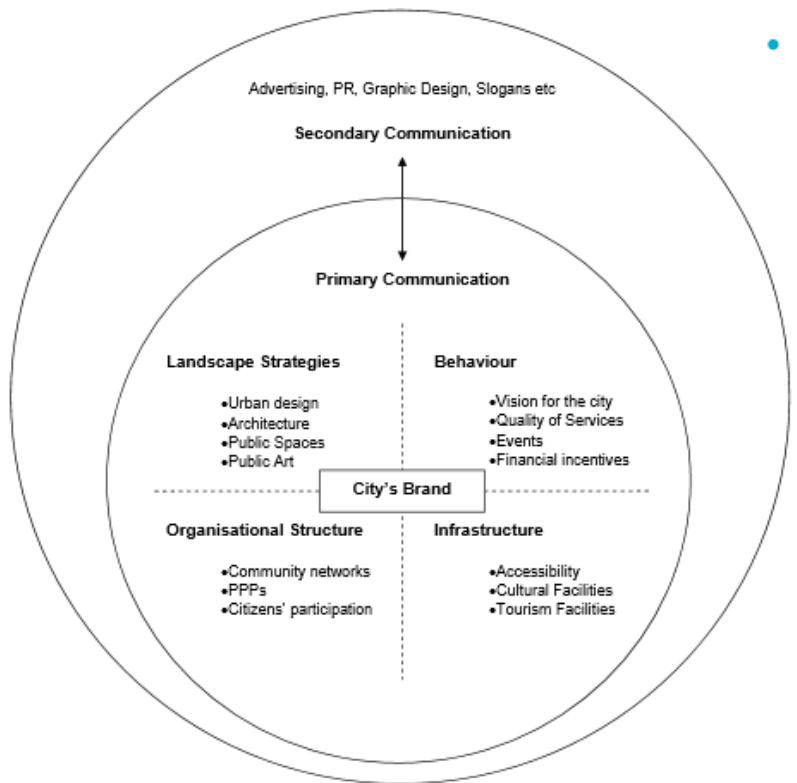

Gambar 1. Theoritical Framework of City Branding Sumber: Kavaratzis, 2008

\section{METODE}

Studi ini menggunakan metode kualitatif dan kuantitatif. Data primer diperoleh dari responden melalui teknik observasi, wawancara dan kuesioner. Observasi dilakukan untuk mempelajari secara langsung kondisi eksisting objek studi, meliputi keadaan fisik, kelengkapan sarana prasarana. Wawancara dilakukan kepada pemerintah khususnya Dinas Pariwisata Kabupaten Belitung selaku pengelola Pantai Tanjung Kelayang untuk mengetahui bentuk kerjasama sektor publik dan privat terhadap destinasi wisata dan apa saja yang telah diupayakan oleh pemerintah untuk pengembangan destinasi wisata serta kepada komunitas dan pelaku usaha di Pantai Tanjung Kelayang untuk mengetahui bentuk partisipasi masyarakat. Responden untuk kuesioner penelitian ini merupakan wisatawan Pantai Tanjung Kelayang sesuai dengan jumlah sampel, Data sekunder diperoleh dari jurnal, literatur, dokumen rencana, BPS dan situs online melalui intenet. Metode analisis yang digunakan yaitu analisis best practice, analisis karakteristik destinasi wisata, analisis persepsi wisatawan terhadap branding dan analisis promosi.

\section{DISKUSI DAN HASIL}

\section{Best Practice}

Pantai Tanjung Kelayang memiliki karakteristik utama yakni berupa pantai yang dijadikan sebagai hub atau titik utama awal aktivitas tur pulau. Penulis mengambil Pantai Cenang, Langkawi dan Pantai Sanur, Bali sebagai objek pembanding dimana kedua pantai memiliki kesamaan karakteristik dengan objek studi. Keberhasilan dari kedua destinasi wisata diatas 
terwujud dalam berbagai indikator dimana persamaannya adalah:

a. Memiliki atraksi khas yang menjadi ciri dan keunikan dari masing-masing pantai. Dimana Pantai Cenang terkenal akan Cenang Night Market sebagai shopping destination yang bebas bea cukai serta Pantai Sanur yang terkenal yang menawarkan pengalaman pemandangan matahari terbit dan atraksi water sports.

b. Kemudahan aksesbiltas dan dapat dijangkau dengan berbagai jenis moda transportasi.

c. Memiliki fasilitas wisata yang lengkap sehingga dapat memenuhi kebutuhan wisatawan dan memberi rasa nyaman. Fasilitas-fasilitas yang ada di pantai maupun di sekitar pantai.

d. Foreign friendly, terdapat money changer dan fasilitas yang dilengkapi dengan bahasa inggris yang memudahkan wisatawan mancanegara saat berkunjung.

e. Adanya partisipasi aktif dari komunitas masyarakat dan kesadaran masyarakat terhadap potensi pariwisata. Komunitas secara aktif ikut terlibat dalam program pariwisata serta mendapat bantuan dari pemerintah.

f. Petugas dan tour agent yang telah terlatih dan terkualifikasi secara resmi sehingga memiliki kemampuan yang baik dalam memberikan pelayanan terhadap wisatawan.

g. Dukungan dari berbagai kerjasama publik-privat maupun antar publik yang dapat mengembangkan potensi pariwisata dalam bentuk pengembangan infrastruktur, SDM maupun insentif keuangan.

h. Memanfaatkan promosi melalui media sosial dan website dengan konten yang menarik dan informatif.

Sedangkan beberapa kekurangan dari kedua benchmark yang kemudian dapat dijadikan pembelajaran yaitu

a. Sebagai efek dari popularitas Pantai Cenang mengakibatkan pantai tersebut menjadi pantai yang padat (crowded). Hal ini dapat menjadi nilai minus karena pantai yang terlalu padat dapat mengurangi kenyamanan wisatawan saat berkunjung.

b. Keterbatasan area parkir

\section{Karakteristik Destinasi Wisata Lansekap}

Pantai Tanjung Kelayang termasuk kedalam tipe dengan karakteristik pantai landai dengan permukaan yang relatif datar serta berpasir yaitu jenis pasir putih yang halus dan ciri khasnya yaitu bebatuan granit besar yang dapat dijumpai di beberapa spot. Pantai dengan karakteristik ini memiliki keunggulan yaitu lebih aman dan banyak untuk dikunjungi. Selain itu juga memiliki ruang yang dapat digunakan untuk mendukung ragam aktivitas pantai atau event dan cocok dibangun dermaga bagi kapal-kapal nelayan berlabuh.

Perairan yang ada tergolong jernih dengan gelombang ombak yang tidak besar serta tidak memiliki biota berbahaya sehingga tergolong aman untuk aktivitas seperti berenang, snorkeling dan tur pulau dengan menggunakan kapal nelayan. Jenis biota laut yang ada terdiri dari beragam jenis ikan, kerang, penyu, bintang laut dan terumbu karang yang bervariasi yang masih terjaga dengan baik. Pantai Tanjung Kelayang memiliki daya tarik yang cukup beragam untuk menarik wisatawan berkunjung. Adapun jenis daya tarik yang dimiliki adalah sebagai berikut. 
Tabel 1. Daya Tarik Wisata

\begin{tabular}{ccc} 
No & Daya Tarik & Jenis \\
\hline 1 & Pulau Lengkuas & Alam \\
\hline 2 & Pulau Batu Garuda & Alam \\
\hline 3 & Pulau dan Goa Kelayang & Alam \\
\hline 4 & Pulau Kepayang & Alam \\
\hline 5 & Pulau Batu Berlayar & Alam \\
\hline 6 & Pulau Burung & Alam \\
\hline 7 & Pulau Pasir & Alam \\
\hline 8 & Biota laut & Alam \\
\hline 9 & Mercusuar & Buatan \\
\hline 10 & Landmark Tanjung Kelayang & Buatan \\
\hline 11 & Festival daerah tahunan & Budaya \\
\hline 12 & Kuliner & Sosial
\end{tabular}

Sumber: Olahan Penulis, 2020

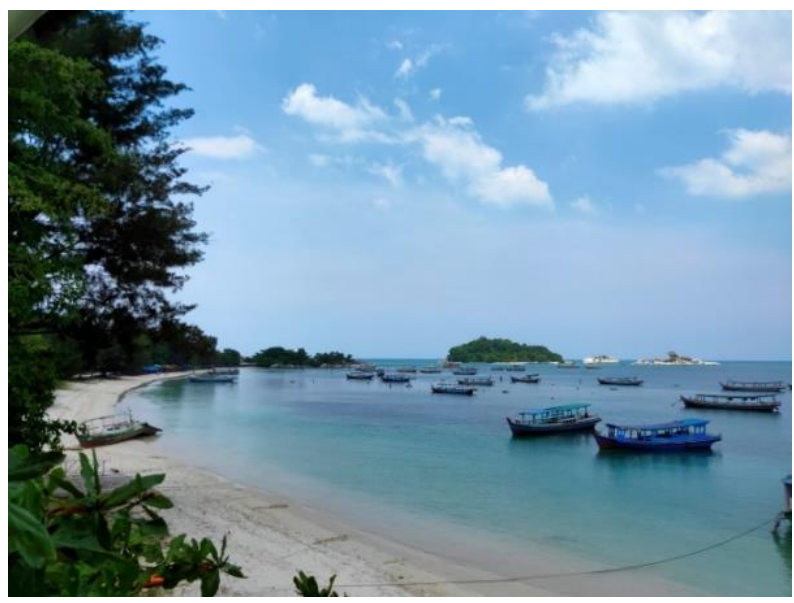

Gambar 2. Pantai Tanjung Kelayang

Sumber: Dokumentasi Penulis, 2020

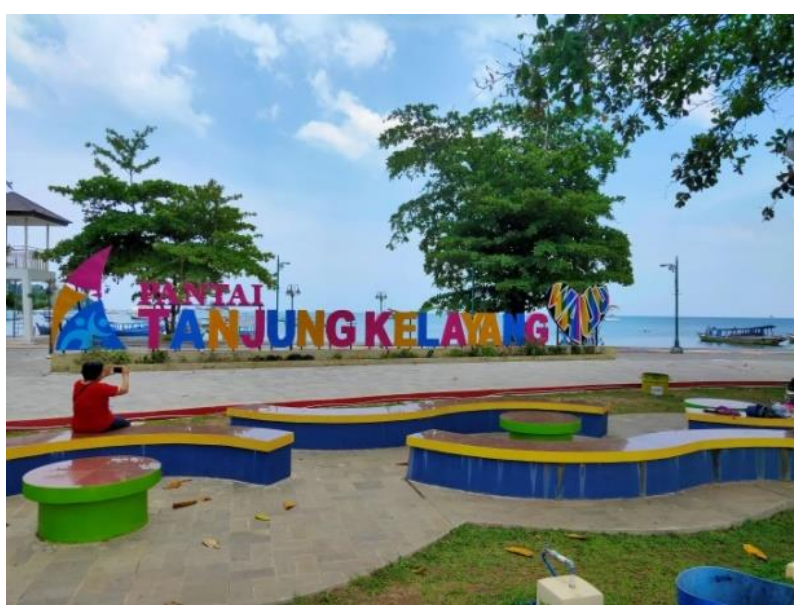

Gambar 3. Landmark Pantai Tanjung Kelayang

Sumber: Dokumentasi Penulis, 2020

\section{Infrastruktur}

Secara makro Pulau Belitung terletak pada lokasi yang strategis dan dapat diakses secara mudah dari domestik maupun internasional. Hal ini dikarenakan Pulau Belitung telah memliki bandara internasional dengan waktu tempuh sekitar 1 jam dari Malaysia dan Singapura maupun Jakarta. Secara mikro, lokasi pantai memang tidak terletak dekat dengan pusat kota namun dapat 
ditempuh dalam waktu sekitar 30-40 menit dan dari bandara memerlukan waktu tempuh sekitar 1 jam. Perjalanan menuju pantai dapat dicapai dengan menggunakan kendaraan pribadi maupun kendaraan umum. Terdapat kendaraan pribadi yang dapat disewakan dan kendaraan umum berupa taxi online dan bus wisata.

Fasilitas akomodasi merupakan hal yang penting bagi wisatawan khususnya wisatawan yang berasal dari luar daerah. Berdasarkan data dari Dinas Paiwisata Kabupaten Belitung, hingga saat ini terdapat 51 hotel dan penginapan dan 20 homestay tersedia. Sebagian besar akomodasi berada di pusat kota, namun hingga kini pembangunan akomodasi mulai banyak dilakukan di kawasan sekitar pantai.

Tabel 2. Standar Kriteria Umum Sarana dan Prasarana Wisata

\begin{tabular}{lll}
\hline \multicolumn{1}{c}{ Sarana } & \multicolumn{1}{c}{ Prasarana } \\
\hline - Rumah makan & $\bullet$ & Kantor pusat informasi (tourism \\
- Tempat pembelanjaan & & information system) \\
- Pos tiket & $\bullet$ Puskesamas/klinik \\
- Toilet/wc umum & $\bullet$ Kos keamanan \\
- Tempat bilas & \\
- Shelter & \\
- Papan penunjuk arah/ papan informasi & \\
- Playing ground & \\
- Tempat ibadah (mushola) & \\
\hline
\end{tabular}

Sumber: Komisi Koordinasi Objek Wisata Alam, 1996

Jika dibandingkan berdasarkan tabel diatas, maka fasilitas eksisting yang terdapat di Pantai Tanjung Kelayang sudah mencukupi standar fasilitas umum yang diperlukan, seperti telah adanya rumah makan, toilet, tempat bilas, shelter, papan informasi, playing ground (sarana bermain anak), tempat ibadah (mushola), puskesmas, pos keamanan dan kapal nelayan demgan kondisi yang baik. Fasilitas lainnya yang tersedia yaitu ampiteater, pendopo, kantor pengelola dan tempat parkir

\section{Peran Stakeholder}

Peran pihak pemerintah, swasta dan komunitas terhadap perkebangan pariwisata belum optimal meskipun banyak potensi. Bentuk partisipasi stakeholder dapat dilihat pada tabel berikut.

Tabel 3. Peran Stakeholder

\begin{tabular}{|c|c|}
\hline Stakeholder & Peran \\
\hline Komunitas & $\begin{array}{l}\text { - Komuniitas nelayan untuk menyewakan kapal masih } \\
\text { baru terbentuk } \\
\text { - } \text { Operasional belum berjalan sesuai SOP sehingga } \\
\text { peran komunitas tidak berpengaruh besar } \\
\text { - Sebanyak } 180 \text { agen perjalanan wisata dan } 22 \text { biro } \\
\text { perjalanan wisata telah terdaftar } \\
\text { - } \quad \text { Belum terdapat pemandu wisata khusus di objek } \\
\text { wisata sehingga agen travel merangkap sebagai tour } \\
\text { guide }\end{array}$ \\
\hline Masyarakat & $\begin{array}{l}\text { - } \quad \text { Bersifat terbuka terhadap wisatawan } \\
\text { - } \quad \text { Kesadaran dan pemahaman masyarakat terhadap } \\
\text { potensi pariwisata masih rendah } \\
\text { Beberapa sudah memiliki usaha di bidang pariwisata } \\
\text { seperti membuka rumah makan, penyewaan alat } \\
\text { berenang, banana boat }\end{array}$ \\
\hline
\end{tabular}




\begin{tabular}{lll}
\hline \multicolumn{1}{c}{ Stakeholder } & \multicolumn{1}{c}{ Peran } \\
\hline Kerjasama publik-privat & $\bullet$ & $\begin{array}{l}\text { Pemerintah bekerjasama dengan Konsorsium Belitung } \\
\text { Maritime Silk Road untuk pembangunan resort dan } \\
\text { hotel standar internasional dan fasilitas pariwisata } \\
\text { lainnya }\end{array}$ \\
\hline Kerjasama publik-publik & Penyelenggaraan program pembinaan masyarakat \\
& serta memfasilitas masyarakat \\
& $\begin{array}{l}\text { Pembangunan infrastruktur berupa jalan } \\
\text { Balai Latihan Kerja (BLK) Belitung membuka rekrutmen } \\
\text { pelatihan kerja barista, tour guide, front office } \\
\text { receptionist, asisten administrasi perkantoran dan } \\
\text { pemandu selam. }\end{array}$ \\
\hline
\end{tabular}

Sumber: Olahan Penulis, 2020

\section{Sikap Kota}

Tabel 4. Kebijakan Rencana Kota RIPPARKAB

Rencana pengembangan terhadap pariwisata dan Pantai Tanjung Kelayang telah mendukung visi kota yang ingin berfokus pada sektor pariwisata. Selain itu, dukungan yang ada juga terlihat dari regulasi dan eksekusi pemerintah sendiri. Berdasarkan sisi kualitas pelayanan, kualitas pelayanan yang ditawarkan sudah cukup baik namun masih terdapat banyak hal yang bisa ditingkatkan lagi, khususnya dalam pemberian pelayanan yang cepat dan memenuhi setiap kebutuhan wisatawan agar wisatawan dapat merasa puas.

Tabel 5. Perbandingan Kualitas Pelayanan

\begin{tabular}{llll}
\hline \multicolumn{1}{c}{ Aspek } & \multicolumn{1}{c}{ Kriteria } & \multicolumn{1}{c}{ Hasil observasi } \\
\hline Keandalan & - Kemampuan untuk & memberikan layanan & Cukup mampu untuk memberikan \\
& pelayanan yang baik kepada wisatawan \\
& - Ketepatan waktu & \\
& - Sesuai dengan prosedur kerja & \\
\hline Responsif & - Menanggapi kebutuhan & $\bullet$ Cukup mampu dalam menanggapi \\
& & kisatawan & kebutuhan wisatawan \\
& - Memberi pelayanan dengan & \\
\hline
\end{tabular}




\begin{tabular}{|c|c|c|}
\hline Aspek & Kriteria & Hasil observasi \\
\hline & cepat & \\
\hline $\begin{array}{l}\text { Jaminan dan } \\
\text { kepastian }\end{array}$ & $\begin{array}{l}\text { - } \text { Komunikasi yang baik } \\
\text { - } \quad \text { Pengetahuan yang luas } \\
\text { - } \quad \text { Sikap yang baik }\end{array}$ & $\begin{array}{l}\text { - Sudah memiliki pengetahuan yang baik } \\
\text { dan mampu menjelaskan informasi } \\
\text { objek wisata, sejarah dan budaya kepada } \\
\text { wisatawan } \\
\text { - Komunikasi dengan menggunakan } \\
\text { bahasa inggris perlu ditingkatkan } \\
\text { - Telah bersikap ramah dan terbuka } \\
\text { dengan wisatawan }\end{array}$ \\
\hline Empati & $\begin{array}{l}\text { - Memahami keinginan dan } \\
\text { kebutuhan wisatawan }\end{array}$ & $\begin{array}{l}\text { - Cukup flexible untuk menyesuaikan } \\
\text { dengan keinginan wisatawan }\end{array}$ \\
\hline Bukti fisik & $\begin{array}{l}\text { - Fasilitas dalam kondisi yang } \\
\text { baik } \\
\text { - Fasilitas lengkap }\end{array}$ & $\begin{array}{l}\text { - Fasilitas saat ini berada pada kondisi } \\
\text { yang baik untuk digunakan } \\
\text { - Fasilitas yang ada sudah memenuhi } \\
\text { kebutuhan umum seperti informasi, } \\
\text { sanitasi, sampah, peralatan renang }\end{array}$ \\
\hline
\end{tabular}

Sumber: Olahan Penulis, 2020

Pantai Tanjung Kelayang kini sudah menjadi salah satu tempat utama perhelatan event/kegiatan khususnya event dengan skala besar. Namun event-event skala tersebut masih terhitung jarang dan tidak selalu dilakukan. Saat ini jenis event yang diadakan kebanyakan bersifat lokal seperti kegiatan perlombaan olahraga atau festival daerah. Event/festival dapat menjadi salah satu faktor penarik kedatangan wisatawan, khususnya evemt berskala nasional dan internasional. Salah satunya yang pernah diadakan yaitu Sail Wakatobi dan Puncak Gerhana Matahari Total. Dinas Pariwisata sendiri telah memberikan perhatian terhadap perhelatan event dengan menetapkan kalender event per bulan dalam satu tahun. Meskipun tidak semua event diadakan di Pantai Tanjung Kelayang.

Pendapatan bagi daerah yang dihasilkan dari kegiatan pariwisata masih belum maksimal. Hal ini disebabkan karena pendapatan hanya berasal dari jasa toilet/ruang bilas dan parkir kendaraan. Belum ada tarif masuk ke dalam pantai. Parkir kendaraan pun dapat dilakukan di luar area kawasan wisata pantai, sehingga tidak dikenakan biaya. Selain itu, warung makan juga terletak di luar wilayah pantai yang dikelola dan berlokasi di lahan milik warga sendiri sehingga tidak ada pendapatan sewa. Selain itu berdasarkan hasil wawancara dengan pihak Dinas Pariwisata, belum terdapat investor di daerah pantai.

Persepsi Wisatawan Terhadap Branding

Tabel 6. Persepsi Wisatawan

\begin{tabular}{lllllllll} 
No & \multicolumn{1}{c}{ Pernyataan } & STS & TS & S & SS & Total & TCR & Kategori \\
\hline 1 & $\begin{array}{l}\text { Lansekap } \\
\text { Atraksi wisata yang unik dan } \\
\text { beragam }\end{array}$ & 1 & 6 & 27 & 62 & 342 & $89 \%$ & $\begin{array}{l}\text { Sangat } \\
\text { Baik }\end{array}$ \\
\hline 2 & $\begin{array}{l}\text { Atraksi utama berupa tur } \\
\text { pulau dan snorkeling }\end{array}$ & 1 & 2 & 25 & 68 & 352 & $92 \%$ & $\begin{array}{l}\text { Sangat } \\
\text { Baik }\end{array}$ \\
\hline 3 & $\begin{array}{l}\text { Dikenal akan pantai pasir } \\
\text { putih dengan bebatuan granit }\end{array}$ & 1 & 1 & 27 & 67 & 352 & $92 \%$ & $\begin{array}{l}\text { Sangat } \\
\text { Baik }\end{array}$ \\
\hline 4 & $\begin{array}{l}\text { Pantai dengan perairan jernih } \\
\text { dan ombak yang tidak besar }\end{array}$ & 0 & 5 & 45 & 46 & 329 & $86 \%$ & $\begin{array}{l}\text { Sangat } \\
\text { Baik }\end{array}$ \\
\hline 5 & $\begin{array}{l}\text { Banyak kegiatan yang dapat } \\
\text { dilakukan }\end{array}$ & 3 & 12 & 47 & 34 & 304 & $79 \%$ & $\begin{array}{l}\text { Sangat } \\
\text { Baik }\end{array}$ \\
\hline 6 & Pantai yang aman untuk & 0 & 4 & 38 & 54 & 338 & $88 \%$ & Sangat \\
\hline
\end{tabular}




\begin{tabular}{|c|c|c|c|c|c|c|c|c|}
\hline No & Pernyataan & STS & TS & $\mathbf{S}$ & SS & Total & TCR & Kategori \\
\hline & dikunjungi & & & & & & & Baik \\
\hline 7 & $\begin{array}{l}\text { Pantai yang tidak terlalu } \\
\text { padat (crowded) }\end{array}$ & 2 & 13 & 43 & 38 & 309 & $80 \%$ & $\begin{array}{l}\text { Sangat } \\
\text { Baik }\end{array}$ \\
\hline 8 & Memiliki kuliner yang khas & 1 & 3 & 21 & 71 & 354 & $92 \%$ & $\begin{array}{l}\text { Sangat } \\
\text { Baik }\end{array}$ \\
\hline \multicolumn{9}{|c|}{ Aksesibilitas } \\
\hline 9 & Lokasi mudah dicapai & 0 & 0 & 32 & 64 & 352 & $92 \%$ & $\begin{array}{l}\text { Sangat } \\
\text { Baik }\end{array}$ \\
\hline 10 & $\begin{array}{l}\text { Terdapat beragam moda } \\
\text { transportasi }\end{array}$ & 0 & 1 & 71 & 24 & 311 & $81 \%$ & $\begin{array}{l}\text { Sangat } \\
\text { Baik }\end{array}$ \\
\hline 11 & Akomodasi mudah ditemukan & 0 & 7 & 58 & 31 & 312 & $81 \%$ & $\begin{array}{l}\text { Sangat } \\
\text { Baik }\end{array}$ \\
\hline 12 & Kondisi fasilitas baik: & & & & & & & \\
\hline a & Toilet/ruang bilas & 2 & 25 & 63 & 8 & 273 & $71 \%$ & Baik \\
\hline $\mathrm{b}$ & Parkir & 1 & 9 & 76 & 10 & 287 & $75 \%$ & Baik \\
\hline c & $\begin{array}{l}\text { Papan penunjuk arah / } \\
\text { papan informasi }\end{array}$ & 0 & 17 & 64 & 15 & 286 & $74 \%$ & Baik \\
\hline $\mathrm{d}$ & Playground & 2 & 14 & 77 & 5 & 281 & $73 \%$ & Baik \\
\hline $\mathrm{e}$ & Tempat ibadah & 1 & 13 & 76 & 6 & 279 & $73 \%$ & Baik \\
\hline $\mathrm{f}$ & $\begin{array}{l}\text { Tempat pembelanjaan } \\
\text { souvenir }\end{array}$ & 2 & 16 & 67 & 11 & 279 & $73 \%$ & Baik \\
\hline $\mathrm{g}$ & Ampiteater & 1 & 15 & 70 & 10 & 281 & $73 \%$ & Baik \\
\hline $\mathrm{h}$ & Pendopo & 0 & 13 & 75 & 10 & 291 & $76 \%$ & $\begin{array}{l}\text { Sangat } \\
\text { Baik }\end{array}$ \\
\hline $\mathrm{i}$ & Kapal nelayan & 2 & 6 & 71 & 19 & 303 & $79 \%$ & $\begin{array}{l}\text { Sangat } \\
\text { Baik }\end{array}$ \\
\hline j & Pos keamanan & 3 & 22 & 65 & 6 & 266 & $69 \%$ & Baik \\
\hline k & Rumah makan & 0 & 4 & 71 & 22 & 309 & $80 \%$ & $\begin{array}{l}\text { Sangat } \\
\text { Baik }\end{array}$ \\
\hline 13 & $\begin{array}{l}\text { Fasilitas lengkap untuk } \\
\text { memenuhi kebutuhan }\end{array}$ & 3 & 9 & 71 & 13 & 286 & $74 \%$ & Baik \\
\hline \multicolumn{9}{|c|}{ Stakeholder } \\
\hline 14 & $\begin{array}{l}\text { Komunitas aktif terlibat dalam } \\
\text { pariwisata }\end{array}$ & 2 & 34 & 44 & 16 & 266 & $69 \%$ & Baik \\
\hline 15 & $\begin{array}{l}\text { Masyarakat bersifat terbuka } \\
\text { dan ramah }\end{array}$ & 1 & 9 & 37 & 49 & 326 & $85 \%$ & $\begin{array}{l}\text { Sangat } \\
\text { Baik }\end{array}$ \\
\hline 16 & $\begin{array}{l}\text { Peran kerjasama pubik- } \\
\text { privat/publik }\end{array}$ & 9 & 38 & 44 & 5 & 237 & $62 \%$ & Baik \\
\hline \multicolumn{9}{|c|}{ Sikap Kota } \\
\hline 17 & $\begin{array}{l}\text { Visi dan rencana kota } \\
\text { mendukung perkembangan } \\
\text { pariwisata }\end{array}$ & 2 & 13 & 43 & 38 & 309 & $80 \%$ & $\begin{array}{l}\text { Sangat } \\
\text { Baik }\end{array}$ \\
\hline 18 & $\begin{array}{l}\text { SDM pariwisata memiliki } \\
\text { kemampuan yang baik dalam } \\
\text { memberikan pelayanan }\end{array}$ & 1 & 8 & 47 & 40 & 318 & $83 \%$ & $\begin{array}{l}\text { Sangat } \\
\text { Baik }\end{array}$ \\
\hline 19 & $\begin{array}{l}\text { cepat dalam menanggapi } \\
\text { kebutuhan wisatawan }\end{array}$ & 4 & 19 & 47 & 26 & 287 & $75 \%$ & Baik \\
\hline 20 & $\begin{array}{l}\text { Komunikasi berjalan dengan } \\
\text { baik }\end{array}$ & 3 & 5 & 68 & 20 & 297 & $77 \%$ & $\begin{array}{l}\text { Sangat } \\
\text { Baik }\end{array}$ \\
\hline 21 & $\begin{array}{l}\text { Pengetahuan dan informasi } \\
\text { yang luas }\end{array}$ & 0 & 3 & 55 & 38 & 323 & $84 \%$ & $\begin{array}{l}\text { Sangat } \\
\text { Baik }\end{array}$ \\
\hline 22 & $\begin{array}{l}\text { Sikap yang baik, ramah dan } \\
\text { sopan }\end{array}$ & 1 & 6 & 27 & 62 & 342 & $89 \%$ & $\begin{array}{l}\text { Sangat } \\
\text { Baik }\end{array}$ \\
\hline
\end{tabular}




\begin{tabular}{lllllllll} 
No & \multicolumn{1}{c}{ Pernyataan } & STS & TS & S & SS & Total & TCR & Kategori \\
\hline 23 & $\begin{array}{l}\text { Memahami keinginan dan } \\
\text { kebutuhan wisatawan }\end{array}$ & 0 & 7 & 62 & 27 & 308 & $80 \%$ & $\begin{array}{l}\text { Sangat } \\
\text { Baik }\end{array}$ \\
\hline 24 & Kebersihan lingkungan & 5 & 17 & 44 & 30 & 291 & $76 \%$ & $\begin{array}{l}\text { Sangat } \\
\text { Baik }\end{array}$ \\
\hline 25 & $\begin{array}{l}\text { Jenis event/festival yang } \\
\text { diadakan menarik }\end{array}$ & 0 & 8 & 37 & 51 & 331 & $86 \%$ & $\begin{array}{l}\text { Sangat } \\
\text { Baik }\end{array}$ \\
\hline 26 & $\begin{array}{l}\text { Biaya wisata terjangkau } \\
27\end{array}$ & 0 & 3 & 47 & 46 & 331 & $86 \%$ & $\begin{array}{l}\text { Sangat } \\
\text { Baik }\end{array}$ \\
\hline $\begin{array}{l}\text { Biaya yang dikeluarkan } \\
\text { diberiman }\end{array}$ & 1 & 8 & 76 & 11 & 289 & $75 \%$ & Baik
\end{tabular}

Sumber: Olahan Penulis, Hasil Kuesioner, 2020

Secara umum citra Pantai Tanjung Kelayang saat ini komponen-komponen pembentuk branding menghasilkan citra yang baik. Selanjutnya dapat terlihat komponen mana yang memiliki citra terbaik dengan persentase tertinggi dimana artinya komponen tersebut merupakan kesan atau gambaran yang dimiliki wisatawan setelah berkunjung ke Pantai Tanjung Kelayang.

- Pantai Tanjung Kelayang dikenal akan cirinya berupa pantai pasir putih dengan bebatuan granit, atraksi utama bagi wisatawan yaitu kegiatan tur pulau dan snorkeling serta kulinernya yang khas.

- Dari sisi aksesbilitas, pencapaian menuju pantai mudah.

- Masyarakat bersifat terbuka dan ramah (friendly atmosphere)

- Sikap yang ditunjukkan melalui pelayanan SDM pariwisata juga baik, ramah dan sopan

- Jenis event/festival yang diadakan menarik

- Biaya wisata yang terjangkau

Adapun beberapa komponen yang perlu ditingkatkan atau dikuatkan yaitu:

- Fasilitas wisata eksisting seperti toilet/ruang bilas, parkir, papan penunjuk arah/papan informasi, playground, tempat ibadah, tempat pembelanjaan souvenir, ampiteater dan pos keamanan

- Fasilitas wisata masih dirasa kurang untuk melengkapi kebutuhan wisatawan

- Partisipasi komunitas dalam kegiatan pariwisata

- Peran kerjasama dari publik-privat maupun publik-publik

- Peran SDM Pariwisata dalam menanggapi kebutuhan wisatawan

- Kualitas barang/jasa yang perlu disesuaikan dengaan biaya wisata yang dikeluarkan agar wisatawan merasa puas.

\section{Promosi}

\section{Media Promosi}

Dalam upaya promosi, Dinas Pariwisata telah menggunakan ragam media promosi yang tertera dalam Tabel 7. Berdasarkan temuan dari lapangan dan hasil pembahasan maka ditarik kesimpulan bahwa dalam aspek media promosi, upaya promosi yang dilakukan telah menggunakan banyak ragam media sebagai sarana promosi. Hal ini merupakan tanda yang bagus karena dengan adanya keberagaman media promosi dapat menambah peluang untuk menjangkau lebih banyak kalangan calon wisatawan agar tertarik untuk berkunjung ke Pantai Tanjung Kelayang. Kecenderungan media yang dipakai ialah publisitas dan melalui festival. 
Tabel 7. Media Promosi

\begin{tabular}{|c|c|c|}
\hline Jenis Promosi & Media & Keterangan \\
\hline \multirow[t]{3}{*}{ Publisitas } & Media cetak & $\begin{array}{l}\text { Materi promosi dalam bentuk majalah, } \\
\text { brosur/pamflet, CD, peta wisata dan booklet yang } \\
\text { dicetak }\end{array}$ \\
\hline & Iklan & $\begin{array}{l}\text { Penempatan iklan dilakukan di media massa cetak } \\
\text { lokal, internet, baliho/billboard yang dipasang } \\
\text { disepanjang jalan serta iklan yang dipasang di } \\
\text { moda-moda transportasi umum seperti pesawat } \\
\text { dan kereta api. }\end{array}$ \\
\hline & Media sosial & instagram, facebook dan website \\
\hline \multirow[t]{2}{*}{ Personal selling } & Table top & $\begin{array}{l}\text { kegiatan untuk mempertemukan travel-travel } \\
\text { agents dari Belitung yang berlaku sebagai seller } \\
\text { dengan travel agents dari kota lain (buyer) } \\
\text { sehingga terjadi transaksi jual-beli paket wisata ke } \\
\text { daerah yang dikunjungi }\end{array}$ \\
\hline & Booth pameran & $\begin{array}{l}\text { Agenda pameran dilakukan seperti di event- } \\
\text { event/mall sebanyak 3-4 kali dalam } 1 \text { tahun }\end{array}$ \\
\hline Festival & & $\begin{array}{l}\text { pengadaan festival tahunan secara berkala } \\
\text { meliputi event berskala lokal hingga internasional }\end{array}$ \\
\hline Promosi penjualan & & $\begin{array}{l}\text { Kerjasama dengan pihak maskapai penerbangan } \\
\text { seperti diskon tiket penerbangan atau diskon paket } \\
\text { wisata. }\end{array}$ \\
\hline
\end{tabular}

Sumber: Olahan Penulis, 2020

\section{Target Wisatawan}

Berdasarkan data yang dikumpullkan melalui kuesioner maka dapat dibuat segmentasi dengan berbagai aspek sebagai pada Tabel 8. Sehingga dapat disimpulkan penetapan target pasar wisatawan potensial sebagai berikut:

1.Wisatawan Domestik

- Kelompok usia remaja dan muda

- Pelajar/mahasiswa

- Family trip

2.Wisatawan Mancanegara

- Asia Tenggara (Singapura, Malaysia)

- Asia Timur (China, Korea, Jepang)

- Eropa (Belanda, Perancis, Jerman, dll)

Tabel 8. Segmentasi Wisatawan

\begin{tabular}{lll}
\hline \multicolumn{1}{c}{ Segmentasi } & \multicolumn{1}{c}{ Aspek } & \multicolumn{1}{c}{ Hasil } \\
\hline Geografis & Wilayah & Dalam negeri \\
\hline Demografis & Kelompok usia & \multicolumn{1}{c}{$<$ Luar negeri } \\
\hline Jenis kelamin & & $18-30$ tahun \\
\hline Tingkah laku & Jenis kelamin & Perempuan \\
\cline { 2 - 3 } & Status Pekerjaan & Tidak bekerja \\
\cline { 2 - 2 } & Partner kunjungan & Keluarga \\
\cline { 2 - 3 } & Media informasi & Teman \\
\cline { 2 - 3 } & & Keluarga/teman \\
\cline { 2 - 3 } & Biaya perjalanan & Sosial media \\
\hline Psikografis & Motivasi kunjungan & Atraksi alam \\
\cline { 2 - 3 } & Tujuan kunjungan & Berenang/snorkeling \\
\hline
\end{tabular}

Sumber: Olahan Penulis, 2020 


\section{Rekomendasi}

Rekomendasi usulan strategi yang mengacu pada komponen-komponen destination branding untuk memperkuat citra destinasi dan membangun sisi kompetitif destinasi wisata.

a. Lansekap

- Menetapkan atraksi wisata yang menjadi ciri khas dan keunikan dari pantai sebagai produk wisata unggulan dalam paket wisata.

- Menambah keragaman atraksi wisata baru

b. Infrastruktur

- Perbaikan kondisi fasilitas wisata eksisting yang esensial bagi wisatawan seperti toilet/ruang bilas, parkir, papan penunjuk arah/papan informasi, playground, tempat ibadah, tempat pembelanjaan souvenir, ampiteater dan pos keamanan

- Penambahan fasilitas wisata lainnya yang saat ini belum tersedia. Hal ini bertujuan untuk melengkapi kebutuhan wisatawan sehingga dapat memberikan rasa nyaman. Selain itu fasilitas juga perlu dipastikan ramah bagi wisatawan mancanegara (foreign friendly). Fasilitas-faslitas tersebut dapat berupa ATM, money changer, tourist information center (TIC), mini market, café/snack bar, toko souvernir, art shop, area parkir, gazebo.

c. Stakeholder

- Peningkatan peran partisipasi komunitas dan masyarakat melalui pembentukan forum/komunitas yang terorganisir, ikut terlibat secara langsung dalam penyelenggaraan kegiatan wisata, adanya kegiatan event/festival yang memberi kesempatan dan ruang bagi masyarakat untuk menampilkan hasil kreatifitas produk usaha wisatanya, mengadakan kemitraan antar usaha pariwisata kecil dan menengah

- Pembentukan lembaga masyarakat yang dapat menaungi dan mendukung usaha masyarakat di bidang pariwisata

- Pengadaan kursus / mentoring bidang pariwisata berakreditasi

- Memberi dorongan insentif dan permodalan usaha wisata

d. Sikap Kota

- Merealisasikan rencana pengembangan yang telah ditetapkan sesuai dengan priotitas seperti pembangunan dermaga apung di Pulau Lengkuas

- Standarisasi dan sertifikasi kompetensi usaha jasa wisata dan sumber daya masnusia

- Penyelenggaraan pendidikan khusus bidang pariwisata

- Melakukan pengembangan jasa wisata baru untuk mendatangkan pendapatan bagi daerah

- Peningkatan skala festival khususnya festival tahunan dari yang bersifat lokal menjadi nasional atau internasional.

\section{Rekomendasi usulan upaya promosi destinasi}

a. Pemilihan media promosi utama

- Word of mouth

- Digital marketing

- Tur agen, influencer atau blogger berperan aktif dalam membantu untuk mempromosikan pariwisata melalui internet dan media sosial.

- Table top ditujukan ke daerah-daerah yang lebih banyak mendatangkan wisatawan.

- Pengembangan kerja sama dalam jangka panjang dengan pihak maskapai atau ticketing.

- Peningkatan skala festival dari yang bersifat lokal menjadi nasional atau internasional.

- Terus bekerja sama dengan restauran, pusat souvenir dan UKM sehingga menjadi bagian dari rangkaian paket wisata 
b. Pemilihan jenis produk utama untuk dipromosikan

- Mayoritas motivasi utama wisatawan ke Pantai Tanjung Kelayang adalah atraksi alam sehingga promosi dapat lebih menonjolkan keindahan dan keunikan dari pantai dan pulau.

- Produk pariwisata utama yang ditawarkan juga dapat merupakan keunikan dari karakteristik dan keunggulan lokasi yang tidak dapat dilakukan di pantai lain yaitu, aktivitas tur pulau.

- Produk wisata yang ditargetkan kepada kelompok usia muda yang menyukai aktivitas berenang/snorkeling sedangkan kelompok usia dewasa tua (31 tahun hingga 55 tahun ke atas) mengarah kepada tur pulau.

- Mempromosikan Pantai Tanjung Kelayang sebagai pantai rekreasi yang cocok untuk keluarga dan anak-anak karena termasuk sebagai pantai yang aman dengan ombak yang tenang.

c. Membina pelatihan komunikasi yang melibatkan masyarakat sehingga promosi tidak hanya menjadi tanggung jawab pihkan pengelola maupun pelaku wisata.

\section{KESIMPULAN DAN SARAN}

\section{Kesimpulan}

Pantai Tanjung Kelayang memiliki potensi besar untuk menjadi pantai yang lebih dikenal banyak orang sebagai salah satu destinasi wisata uggulan Belitung. Untuk memiliki branding yang kuat maka sebuah destinasi wisata perlu memastikan bahwa wisatawan akan mendapatkan pengalaman yang baik dari kunjungan wisatanya. Secara lansekap, Pantai Tanjung Kelayang memiliki karakteristik pantai yang unik dengan keindahan alam pantai dan lautnya. Infrastruktur yang ada mendukung kegiatan wisata, namun dapat diperlengkapi lagi. Peran stakeholder dalam kegiatan pariwisata juga sangat signifikan. Komunitas, masyarakat lokal, pihak swasta dan pemerintah bersama-sama perlu turut aktif berpartisipasi dalam kegiatan pariwisata. Selain itu, sikap kota dalam mendukung pariwisata juga penting. Hal ini dapat diindikasikan melalui rencana kota, kualitas pelayanan yang ditawarkan, dan event yang diadakan. Berdasarkan hasil studi, Pantai Tanjung Kelayang masih perlu melakukan perbaikan atau peningkatan pada aspekaspek tersebut. Upaya penguatan branding juga tidak hanya sampai disitu saja. Diperlukan juga upaya promosi agar branding dapat semakin diketahui banyak orang. Bentuk informasi dan cara penyampaian yang tepat penting agar upaya promosi dapat efektif.

\section{Saran}

a. Perlunya penetapan strategi dalam mengembangkan pariwisata untuk melengkapi unsurunsur pariwisata yang masih kurang

b. Perlunya melakukan upaya promosi yang efektif untuk mempromosikan destinasi wisata

c. Masyarakat juga perlu bekerjasama dalam partisipasi pengembangan pariwisata dan sadar akan potensi wisata

\section{REFERENSI}

Balakrishnan, M. S. (2009). Strategic Branding of Destinations: A Framework. European Journal of Marketing.

Blain (2005). Destination Branding: Insight and Practices from Destination Management Organizations.

Bornhorst T, J. R. (2009). Determinants of Tourism Successs for DMOs and destinations: An Empirical Examination of Stakeholders' Perspective. Tourism Management.

Kavaratzis, M. (2008). From City Marketing to City Branding. An Interdisplinary Analysis with Reference to Amsterdam, Budapest and Athens. Groningen: Groningen University. 
Ritchie, B. R. J. (1998). The Branding Of Tourism Destinations. A Basic Report for Presentation to the 1998 Annual Congress of the International Association of Scientific Experts in Tourism, Marrakech.

Robert Christie Mill, A. M. (1984). The Tourism System: An Introductory Text. NJ: Prentice Hall. Winardi. (2003). Manajemen Perilaku Organisasi. Jakarta: Kencana.

Yoeti, A. (2002). Pemasaran Pariwisata Terpadu. Bandung: Angkasa. 